\title{
Relationship between bronchial reversibility and tracheobronchial clearance in patients with chronic bronchitis
}

\author{
M Moretti, M T Lopez-Vidriero, D Pavia, S W Clarke
}

\begin{abstract}
Background - Patients with chronic bronchitis show a large intersubject variation in sputum rheology, tracheobronchial clearance, and reversibility of airflow obstruction to $\beta_{2}$ agonists. The bronchial mediators which are known to cause bronchoconstriction, mucosal oedema, mucus hypersecretion, and cough can also affect mucociliary transport. The aim of this study was to ascertain whether changes in tracheobronchial clearance and sputum rheological properties in patients with chronic bronchitis were associated with a specific degree of airflow reversibility assessed as the bronchial response to an inhaled $\beta_{2}$ agonist (fenoterol $400 \mu \mathrm{g}$ ). Methods - Bronchial reversibility (percentage change in baseline forced expiratory volume in one second $\left(F_{E V}\right)$ ) was measured in 26 patients with chronic bronchitis on three separate occasions, at least one week apart. Tracheobronchial clearance was evaluated by a non-invasive radioaerosol technique, and an oscillatory viscometer was used for measuring sputum apparent viscosity and elasticity. The number of coughs (productive and nonproductive coughs), the wet weight of sputum, and its radioaerosol content were recorded during the six hour clearance period, as well as the 24 hour sputum production.

Results - The change in $\mathrm{FEV}_{1}$ after fenoterol was less than $15 \%$ in 12 patients and more than $15 \%$ in 14 . Patients with airways reversibility of more than $15 \%$ had faster tracheobronchial clearance, more coughs, lower sputum viscosity and elasticity, and larger 24 hour sputum production than those with airways reversibility of less than $15 \%$.

Conclusions - In patients with chronic bronchitis a large bronchodilator response is associated with faster clearance of mucus by mucociliary transport and coughing.

(Thorax 1997;52:176-180)
\end{abstract}

Keywords: bronchial reversibility, chronic bronchitis, cough, rheology, sputum, tracheobronchial clearance.

Dr M Moretti.

Received 23 December 1992 Returned to authors 28 May 1993

Revised version received

25 July 1996

Accepted for publication

1 August 1996

Patients with chronic bronchitis have a wide range of impairment of tracheobronchial clearance and of the rheological properties of secretions. ${ }^{12}$ Furthermore, many have de- creased airway obstruction after inhalation of $\beta_{2}$ agonists which is sometimes as great as that found in asthma. ${ }^{3}$ The bronchial mediators which are known to cause bronchoconstriction, mucosal oedema, mucus hypersecretion, and cough can also affect mucociliary transport, but no information is available on the distribution and on the relationship between reversibility of airway obstruction and the impairment of tracheobronchial clearance in chronic bronchitis. ${ }^{4-7}$

Hypothetically, patients with chronic bronchitis who have a substantial bronchodilator response might show some characteristics of bronchial asthma such as higher values for the viscoelastic properties of sputum and greater impairment of tracheobronchial clearance.

The aim of this study was to ascertain whether the degree of bronchial reversibility in patients with chronic bronchitis was associated with changes in tracheobronchial clearance and sputum rheological properties in two groups selected on the basis of the bronchodilator response to a $\beta$ agonist of more or less than $15 \%$ of the baseline forced expiratory volume in one second $\left(\mathrm{FEV}_{1}\right)$.

\section{Methods}

PATIENTS

Twenty six patients (23 men) with airways obstruction $\left(\mathrm{FEV}_{1}<70 \%\right.$ predicted), who fulfilled the criteria of chronic bronchitis according to the UK Medical Research Council's definition, ${ }^{8}$ were included in the study. All remained clinically stable throughout the study period.

\section{PULMONARY FUNCTION TESTS}

In each patient baseline pulmonary function tests comprising forced vital capacity (FVC), forced expiratory volume in one second $\left(\mathrm{FEV}_{1}\right)$, maximum-mid expiratory flow rate at $25-75 \%$ of FVC (MMFR $\left.{ }_{25-75}\right)$ were measured using a dry bellows spirometer (Vitalograph) and peak expiratory flow rate (PEFR) was measured with a Wright peak flow meter.

\section{BRONCHODILATOR RESPONSE}

The patients withheld their inhaled bronchodilator therapy and oral theophylline for the preceding six hours. The FEV 1 was measured three times and the highest of three technically acceptable readings was recorded. The measurements were repeated 20 minutes after in- 
haling two puffs of fenoterol $(400 \mu \mathrm{g})$ from a metered dose inhaler, with a one minute interval between puffs. The bronchodilator response was evaluated as the percentage change in $\mathrm{FEV}_{1}$ from the baseline value (pre-bronchodilator inhalation value).

Reversibility was assessed three times in each patient, always on a different day from the tracheobronchial clearance measurement. In 16 patients these assessments were carried out at monthly intervals the day before the measurements of tracheobronchial clearance were conducted. In the remaining 10 patients, in whom only one reversibility test was carried out at the time the tracheobronchial clearance was measured, the bronchodilator response was assessed further at weekly intervals in order to confirm the previous observations. Based on the mean level of reversibility subsequently assessed, the patients were divided into two groups in accordance with most of the studies on bronchodilator response after $\beta$ agonist inhalation in chronic bronchitis: ${ }^{310}$ patients with bronchial reversibility of $<15 \%$ (group 1) and those with bronchial reversibility of $15 \%$ or more (group 2). An improvement of 15\% over the initial $\mathrm{FEV}_{1}$ after the $\beta$ agonist challenge was taken as evidence of reversible airway obstruction. ${ }^{1112}$

The study was approved by the local ethics committee and all patients gave written informed consent for participating in the study.

\section{TRACHEOBRONCHIAL CLEARANCE}

A radioaerosol technique was used to measure tracheobronchial clearance in a non-invasive manner, as previously described in detail. ${ }^{7}$ Each patient discontinued all the bronchodilator therapies six hours before the measurement of tracheobronchial clearance. The subjects inhaled $5 \mu \mathrm{m}$ polystyrene particles labelled with the radionuclide technetium-99m using a standardised procedure. ${ }^{13}$ Radioactivity in the lung was measured by suitably collimated anterior and posterior scintillation counters immediately after inhalation at 30 minute intervals for six hours and a final count was made at 24 hours. The lung burden at 24 hours, expressed as percentage of the initial deposited radioactivity, was taken to represent alveolar deposition (AD) - that is, the amount of radioactivity deposited in the non-ciliated airways and alveoli. The initial topographical distribution of the radioaerosol within the lung was assessed with a large field of view gamma camera (International General Electric) interfaced with a computer and the lung margins were delineated by a ventilatory scan with krypton- $81 \mathrm{~m}$ gas. The penetration index (PI) was defined as the ratio of peripheral to central zone radioactivity for the radioaerosol relative to that of ${ }^{81 \mathrm{~m}} \mathrm{Kr}$ gas. ${ }^{14}$

Tracheobronchial clearance at six hours after inhalation was expressed as the percentage of the initial tracheobronchial deposition retained at six hours and corrected for productive coughing by adding the radioactivity measured in the sputum to the observed retention curve at the time when it was produced. ${ }^{15}$ In fact, cough accelerates the movement of the radioaerosol particles in the airways, modifying the physiological process of the radioaerosol clearance by the ciliated system. A more useful and accurate way of expressing the results is by calculating the area under the tracheobronchial clearance curve (AUC) using the trapezoidal rule - a large AUC indicates slow tracheobronchial clearance and a small AUC indicates fast tracheobronchial clearance. We divided the six hour tracheobronchial clearance measurement into two periods since this is a more useful and accurate way of expressing the results. ${ }^{16} \mathrm{~A}$ six hour period is sufficient to achieve complete clearance of the radioaerosol in normal subjects but patients with chronic bronchitis in whom mucociliary clearance is impaired require a period longer than six hours to achieve a complete clearance. Since observations cannot be prolonged for more than six hours for practical reasons, the division of AUC into two periods allows the process of clearance to be followed better. Hence, the tracheobronchial clearance was expressed at three different time intervals: 0-3 hours (AUC 0-3 h), 3-6 hours (AUC 3-6 h), and 0-6 hours (AUC 0-6h).

To avoid changes in radioaerosol deposition, tracheobronchial clearance measurements were done on the day after the reversibility studies when the patients were stable. In 10 patients measurement of their tracheobronchial clearance was carried out twice over a one year period and in one patient three times. In patients with more than one measurement of tracheobronchial clearance the results were expressed as the arithmetical mean.

During the tracheobronchial clearance runs the number of coughs was recorded as well as the wet weight and the radioactive content of all the sputum samples.

\section{SPUTUM RHEOLOGICAL STUDIES}

Apparent viscosity and elasticity were measured using a Contraves Low Shear 30 sinus viscometer at a frequency of $0.352 \mathrm{~Hz}$. The sputum samples produced during the first three hours of the tracheobronchial clearance observations were studied. When more than one sample was produced the arithmetical mean was obtained. In the 11 patients who underwent the tracheobronchial clearance run on two or three occasions during a one year period, the viscoelastic results were expressed as the arithmetical mean.

\section{DAILY SPUTUM PRODUCTION}

Each patient collected the sputum produced during the 24 hours before the tracheobronchial clearance assessment and the amount was recorded as wet weight.

DATA ANALYSIS

The Student's $t$ test for unpaired data was used in the statistical analysis. 
Table 1 Mean (SE) physical characteristics, smoking habit, pulmonary function indices, alveolar deposition (AD), and penetration index (PI) of the initially deposited radioaerosol for patients with chronic bronchitis with bronchial reversibility of $<15 \%$ (group 1) and $>15 \%$ (group 2)

\begin{tabular}{lll}
\hline & $\begin{array}{l}\text { Group } 1 \\
(n=12)\end{array}$ & $\begin{array}{l}\text { Group 2 } \\
(n=14)\end{array}$ \\
\hline Age (years) & $70(3)$ & $66(5)$ \\
No. of women & 1 & 2 \\
Pack years & $60(7)$ & $66(3)$ \\
FEV (\% pred) & $53(8)$ & $40(2)$ \\
PEFR (\% pred) & $54(6)$ & $43(3)$ \\
FVC (\% pred) & $84(9)$ & $70(5)$ \\
MMFR $_{25-75}(\%$ pred) & $23(4)$ & $16(2)$ \\
FEV $(\%$ change after & $10.3(0.9)$ & $26.6(2.0)$ \\
fenoterol) & $27(12)$ & $24(6)$ \\
AD (\%) & $0.43(0.29)$ & $0.45(0.17)$ \\
PI &
\end{tabular}

$\mathrm{FEV}_{1}=$ forced expiratory volume in one second; $\mathrm{FVC}=$ forced vital capacity; $\mathrm{MMFR}_{25-75}=$ maximum mid expiratory flow at $25-75 \%$ of FVC.

Table 2 Mean (SE) results of tracheobronchial clearance measurements (AUC), number of coughs, sputum rheological properties, and sputum production for patients with chronic bronchitis with bronchial reversibility of $<15 \%$ (group 1) and $>15 \%$ (group 2)

\begin{tabular}{lcc}
\hline & Group 1 & Group 2 \\
\hline AUC & $390(19)$ & $350(20)$ \\
0-6 hours & $251(13)$ & $211(14)$ \\
0-3 hours & $188(6)$ & $148(4)^{*}$ \\
3-6 hours & & \\
Total coughs (n) & $14.1(3.0)$ & $22.6(5.8)$ \\
0-6 hours & $9.0(2.1)$ & $14.1(4.0)$ \\
0-3 hours & $5.9(1.3)$ & $8.5(1.9)$ \\
3-6 hours & & \\
Sputum production (g) & $2.8(0.8)$ & $3.8(1.0)$ \\
0-6 hours & $11.2(1.0)$ & $27.1(3.0)^{*}$ \\
daily & & \\
Sputum rheological properties & \\
Viscosity (mP.s) & $646(89)$ & $339(85)^{*}$ \\
Elasticity (mP) & $3721(686)$ & $1701(305)^{* *}$ \\
\hline * p<0.05; ** p<0.02. & &
\end{tabular}

\section{Results}

PATIENTS

The mean (SE) physical characteristics, smoking habits, baseline lung function indices, AD and PI values are given in table 1 . Fourteen patients were current smokers and 12 had ceased smoking at least one year before the study. Both smokers and ex-smokers were matched well in groups 1 and 2 .

BRONCHIAL REVERSIBILITY

Twelve of the 26 patients (46\%) were in group 1 and $14(54 \%)$ in group 2 . There was a trend for the observed $\mathrm{FEV}_{1}$ pre-reversibility to be higher in group $1(1.42(0.16) 1)$ than in group $2(1.09(0.08) 1)$ but this was not statistically significant. After reversibility the $\mathrm{FEV}_{1}$ was also not significantly higher in group 1 $(1.58(0.19) 1)$ than in group $2(1.34(0.05) 1)$. The percentage change after fenoterol was $+10.3(0.9) \%$ and $+26.6(2.0) \%$, respectively, for groups 1 and $2(\mathrm{p}<0.001)$. There was a low intra-patient coefficient of variation $(<10 \%)$ in the bronchial reversibility test among the patients included in the study.

TRACHEOBRONCHIAL CLEARANCE

The six hour tracheobronchial clearance results are shown in table 2. The tracheobronchial clearance was slower in group 1 than in group 2 . AUC 0-6 was smaller in group 2 (350 (20)\%/ hour, indicating a faster clearance) than in group 1 (390 (19)\%/hour), although the difference did not reach statistical significance. The values of AUC between 0-3 hours and 3-6 hours were always greater in group 1 than in group 2, the difference being significant for 3-6 hours $(\mathrm{p}<0.05)$.

COUGH

Patients with bronchial reversibility of $>15 \%$ coughed more than those with bronchial reversibility of $<15 \%$ but no statistical difference between the two groups was observed in the mean value of total number of coughs for the three observation periods. The mean number of coughs in the three observation periods for the two groups is given in table 2 .

\section{SPUTUM PRODUCTION AND SPUTUM}

RADIOACTIVE CONTENT

The amount of sputum expectorated during the six hour observation period was greater in the patients with bronchial reversibility of $>15 \%$ than in those with bronchial reversibility of $<15 \%$, although statistical significance was not attained (table 2).

The sputum radioaerosol content for the six hour observation period (expressed as percentage of the initial tracheobronchial radioaerosol deposition) did not differ between group 1 (10.4 (3.3)\%) and group 2 (11.2 (3.9)\%).

The daily sputum production in group 2 was significantly greater $(\mathrm{p}<0.05)$ than in group 1 (table 2).

\section{SPUTUM RHEOLOGICAL PROPERTIES}

Five patients (two in group 1 and three in group 2) of the 26 did not produce sputum during the six hour observation period. Apparent viscosity $(\mathrm{p}<0.05)$ and elasticity $(p<0.02)$ were both significantly lower in group 2 than in group 1.

\section{Discussion}

The results of this study indicate that patients with chronic bronchitis who have airway reversibility of $>15 \%$ of baseline $\mathrm{FEV}_{1}$ differ from those with bronchial reversibility of $<15 \%$ in having a higher number of coughs, more bronchial hypersecretion, lower sputum rheological properties, and faster tracheobronchial clearance.

The data relating to bronchial reversibility observed in our patients with chronic bronchitis are in agreement with those reported by other authors in that a large proportion had a bronchodilator response to a $\beta_{2}$ agonist similar to that of asthmatics. ${ }^{17-20}$ As expected, the patients had a wide range of impairment of tracheobronchial clearance and of rheological properties of the sputum. ${ }^{12}$ Although the tracheobronchial clearance was markedly impaired in both groups compared with healthy 
controls, ${ }^{21}$ patients in group 2 cleared better than those in group 1 . The AUC at the different time intervals was smaller in group 2 than in group 1 , especially in the 3-6 hour period. The faster clearance of the radioaerosol in group 2 progressively increased the difference in airway radioaerosol retention between the two groups. Hence the difference between groups 1 and 2 progressively increased with time, becoming significant in the last three hours of the six hour observation period. This difference in tracheobronchial clearance between the two groups was not attributable to differences in the initial topographical distribution of the radioaerosol since the mean values of alveolar deposition and penetration index were similar in both groups.

Patients with bronchial reversibility of $>15 \%$ coughed more and produced a larger amount of mucus with a higher radionuclide content than those with bronchial reversibility of $<15 \%$, especially at 3-6 hours, but the differences were not statistically significant. It may be that the difference in the tracheobronchial clearance between the two groups is due to the effect of coughing. Cough is considered one of the main mechanisms which influences bronchial clearance in chronic bronchitic patients with chronic expectoration..$^{223}$ It is unlikely that the difference in tracheobronchial clearance between the two groups could be due to the two-phase flow mechanism by respiration at tidal volume. The velocity profile of expiratory airflow should theoretically be higher in patients in group 1 who had better lung function than those in group 2. The larger volume of sputum in patients in group 2 could favour the two-phase gas-liquid interaction; once the mucus layer increases in the airways and reaches the critical thickness it can be transported by the expiratory airflow at tidal volume, at least in the large airways. The efficacy of mucus transport by the two-phase flow mechanism in the peripheral airways is disputed since the critical flow rate may not be achievable in the peripheral bronchi. ${ }^{2425}$

The rheological values of the sputum of the 26 patients had a wide range; this is in agreement with previous studies ${ }^{26}$ but, despite this, the mean value of sputum viscosity and elasticity were significantly lower in patients in group 2 than those in group 1 . This difference in sputum viscoelastic properties could contribute partially to the difference in tracheobronchial clearance between the two groups. In vitro studies using the frog palate preparation have shown that the transport rate of human sputum samples is influenced by the mucus rheological properties, especially elasticity. ${ }^{27-29}$ Furthermore, in patients with chronic bronchitis a significant positive correlation was reported in vivo between tracheobronchial clearance and the relative transport of sputum measured on the ciliated frog palate preparation. ${ }^{23}$

Patients in group 2 also differed from those in group 1 in producing more sputum within the six hour tracheobronchial clearance measurement as well as in the 24 hour collection. The greater sputum production could contribute to the faster tracheobronchial clearance in group 2 since a significant positive correlation has been reported between tracheobronchial clearance and sputum production in patients with chronic bronchitis. ${ }^{30}$

These results indicate that differences in bronchial reversibility are associated with various degrees of mucus clearance in chronic bronchitis. These data are supported by the fact that inflammatory mediators are known to influence both the mechanisms involved in tracheobronchial clearance such as mucus secretion, ${ }^{31-33}$ ciliary activity, ${ }^{3435}$ coughing, ${ }^{36-38}$ and bronchial reversibility. Further studies are indicated to ascertain whether the degree of inflammation and the related mediators or the type of cellular components are the contributing factors.

1 Pavia D, Sutton P, Agnew JE, Lopez-Vidriero MT, Newman SP, Clarke SW. Measurement of bronchial mucociliary clearance. Eur $\mathcal{F}$ Respir Dis 1983;64(Suppl 127):41-56.

2 Lopez-Vidriero MT, Reid L. Chemical markers of bronchial and serum glycoproteins in mucoid and purulent sputum from various diseases. Am Rev Respir Dis 1978;117:46577

3 Anthonisen NR, Wright EC, and the IPPB Trial Group. Bronchodilator response in chronic obstructive disease. Am Rev Respir Dis 1986;133:814-9.

4 Richardson PS, Peatfield AC. Protection of the respiratory tract mucus production: a review. $\mathcal{F} R$ Soc Med 1980;73: 123-6.

5 Lopez-Vidriero MT, Reid L. Pathological changes in asthma In: Clark TJH, Godfrey S, eds. Asthma. London: Chapman and Hall, 1983:79-98.

6 Coles SJ, Bhaskar KR, O'Sullivan DD, Neill KH, Reid L. Airway mucus composition and regulation of its secretion by neuropeptides in vitro. In: Nugent J, O'Connor $M$, eds. Mucus and mucosa (Ciba Foundation Symposium 109). London: Pitman Publishing Ltd, 1984:40-60.

7 Pavia D, Lopez-Vidriero MT, Clarke SW. Mediators and mucociliary clearance in asthma. Bull Eur Physiopathol Respir 1987;23:89-94s.

8 Medical Research Council. Definition and classification of chronic bronchitis for clinical and epidemiological purchronic bronchitis for clinical
poses. Lancet 1965;i:775-9.

9 Meslier N, Racineux JL, Six P, Lockhart A. Diagnostic value of reversibility of chronic airway obstruction to separate asthma from chronic bronchitis: a statistical approach Eur Respir F 1989;2:497-505.

10 Nisar M, Walshaw M, Earis JE, Pearson MG, Calverley PMA. Assessment of reversibility of airway obstruction in patients with chronic obstructive airways disease. Thorax 1990;45:190-4

11 American Thoracic Society. Committee on diagnostic standards for nontuberculous respiratory diseases, chronic bronchitis, asthma and pulmonary emphysema. Am Rev Respir Dis 1962;85:762-8.

12 American Thoracic Society. ATS statements - Snowbird workshop on standardisation of spirometry. Am Rev Respir Dis 1979;119:831-8.

13 Pavia D, Bateman JRM, Sheahan NF, Agnew JE, Clarke SW. Tracheobronchial mucociliary clearance in asthma during remission. Thorax 1985;40:171-5.

14 Agnew JE, Pavia D, Clarke SW. Airways penetration of inhaled radioaerosol: an index of small airways function? Eur f Respir Dis 1981;62:239-55.

15 Fazio F, Lafortuna C. Effects of inhaled salbutamol on mucociliary clearance in patients with chronic bronchitis. Chest $1981 ; 80$ (Suppl):827-30.

16 Millar AB, Agnew JE, Newman SP, Lopez-Vidriero MT, Pavia D, Clarke SW. Comparison of nasal and tracheobronchial clearance by similar techniques in normal subjects. Thorax 1986;41:783-6.

17 Yan K, Salome M, Woolkock AJ. Prevalence and nature of bronchial hyperresponsiveness in subjects with chronic obstructive pulmonary disease. Am Rev Respir Dis 1985; 132:25-9.

18 Barter CE, Campbell AH. Relationship of constitutional factors and cigarette smoking to decrease one second forced expiratory volume. Am Rev Respir Dis 1976;113: 305-14.

19 Paine CB, Chester EH, Hsi BP. Airway responsiveness in chronic obstructive pulmonary disease. Am f Med 1967; 42:554-66.

20 Oppenheimer EA, Rigetto M, Fletcher CM. Airways obstruction before and after isoprenaline, histamine, and prednisolone in patients with chronic obstructive bronchitis. Lancet 1968;i:552-7.

21 Del Donno M, Pavia D, Agnew JE, Lopez-Vidriero MT, Clarke SW. Variability and reproducibility in the measurement of tracheobronchial clearance in healthy subjects and patients with different obstructive lung diseases. Eur Respir f 1988;1:613-20. 
22 Camner P, Mossberg B, Philipson K, Strandberg K. Elimination of test particles from the human tracheo-bronchial tract by voluntary coughing. Scand F Respir Dis 1979;60: 56-62.

23 Puchelle E, Zahm JM, Girard F, Bertrand A, Polu JM, Aug $\mathrm{F}$, et al. Mucociliary transport in vivo and in vitro. Relation to sputum properties in chronic bronchitis. Eur f Respir Dis 1980;61:254-64.

24 Blake J. On the movement of mucus in the lung. F Biochem 1975;8:179-90.

25 Kim CS, Rodriguez CR, Eldrige MA, Sackner MA. Criteria for mucus transport in the airways by two-phase gas-liquid flow mechanism. F Appl Physiol 1986;60:901-7.

26 Mitchell-Heggs P, Palfrey AJ, Reid L. The elasticity of sputum at low shear rates. Biorheology 1974;11:417-26.

27 Dulfano MJ, Adler KB. Physical properties of sputum. VII. Rheologic properties and mucociliary transport. Am Rev Respir Dis 1975;112:341-7.

28 Puchelle E, Girard F, Zahm JM. Rheologie des secretions bronchiques et transport muco-ciliare. Bull Eur Physiopathol Respir 1976;12:771-9.

29 Shih CK, Litt M, Khan MA, Wolf DP. Effect of non dialyzable solid concentration and viscoelasticity on ciliary transport of tracheal mucus. Am Rev Respir Dis 1977;115: 989-95.

30 Agnew JE, Little F, Pavia D, Clarke SW. Mucus clearance from the airways in chronic bronchitis - smokers and exsmokers. Bull Eur Physiopathol Respir 1982;18:473-84.
31 Lopez-Vidriero MT, Das I, Smith P, Reid L. Bronchial secretion from normal human airways after inhalation of prostaglandin F2 alpha, acetylcholine, histamine and citric acid. Thorax 1975;32:734-9.

32 Maron Z, Shelhamer JH, Bach MK, Morton DR, Kaliner $M$. Slow reacting substances, leukotriene $\mathrm{C} 4$ and $\mathrm{D} 4$, increase the release of mucus from human airways in vitro. Am Rev Respir Dis 1982;126:449-51.

33 Rich B, Peatfield AC, Williams JP, Richardson PS. Effects of prostaglandins E1, E2 and F2 on mucin secretion from human bronchi in vitro. Thorax 1984;39:420-3.

34 Smallman LA, Hill SL, Stockley RA. Reduction of ciliary eat frequency in vitro by sputum from patients with bronchiectasis: a serine proteinase effect. Thorax 1984;39:6637.

35 Sykes DA, Wilson R, Greestone M, Currie DC, Steinfor C, Cole PJ. Deleterious effect of purulent sputum so on human ciliary function in vitro: at least two factors identified. Thorax 1987;42:256-61.

36 Simmonsson BG, Jacobs FM, Nadel JA. Role of autonomic nervous system and the cough reflex in the increased responsiveness of airways in patients with obstructive airways disease. F Clin Invest 1967;46:1812-8.

37 Costello JF, Dunlop LS, Gardiner PJ. Characteristics of prostaglandin induced cough in man. Brf Clin Pharmacol 1985;20:355-9.

38 Choudry NB, Fuller RW, Pride NB. Sensitivity of the human cough reflex: effect of inflammatory mediators prostaglandin $\mathrm{E}_{2}$, bradykinin and histamine. Am Rev Respir Dis 1989;140:137-41. 